\title{
'Utopia': A New Zantedeschia aethiopica Cultivar
}

Juan Guillermo Cruz-Castillo

\author{
Universidad Autónoma Chapingo, Centro Regional Universitario Oriente, \\ Huatusco, Veracruz 94100, Mexico
}

Additional index words. Araceae, arum lily, calla, new ornamentals, perennial calla

'Utopia' [Zantedeschia aethiopica (L.) K. Spreng] is a perennial calla developed by Chapingo Autonomous University, Mexico. The calla belongs to the Araceae family and is an ornamental native of Africa (Kuehny, 2000). In Mexico it is popular and is used for weddings and other celebrations. Most of the calla produced in Mexico are a perennial type with white spathes. In Latin America, this calla also grows in Argentina, Bolivia, Brazil, Colombia, Ecuador, and Guatemala. In some markets of Mexico, the perennial cultivar Green Goddess is found. It is characterized by green spots mixed with white in the spathe (Cruz-Castillo et al., 2008). Before the release of 'Utopia', another perennial calla named 'Deja Vu' was registered in Mexico. Its spathe is green, pink, and white (Cruz-Castillo and Torres-Lima, 2017). Most calla breeding has been carried out in the Netherlands, New Zealand, and the United States, and focuses on deciduous callas (Kuehny, 2000).

\section{Origin}

'Utopia' was selected in Huatusco, Veracruz, Mexico, in a tropical highland (lat. $19^{\circ} 11^{\prime} 12.48^{\prime \prime} \mathrm{N}$, long. $97^{\circ} 11^{\prime} 13.75^{\prime \prime} \mathrm{W}$; elevation, $1950 \mathrm{~m}$ ) with an average annual rainfall of $1825 \mathrm{~mm}$ and an average temperature of $17^{\circ} \mathrm{C}$.

Once 'Utopia' had been identified, its characterization was carried out using the guidelines for the execution of the examination of the distinction, homogeneity, and stability of Zantedeschia sp. (International Union for the Protection of New Varieties of Plants, 2011).

A clone was originated by crossing 'Deja Vu' (father) with seedlings of 'Pink Mist' (mother). It is an F1 plant. 'Deja Vu' has breeder title no. 1478, granted by the National Seed Inspection and Certification System of Mexico.

From 250 individuals originated by the crosses, 'Utopia' was selected. To obtain these individuals, 10 'Deja Vu' plants and ' 10 Pink Mist' seedlings were used. The crosses were carried out manually in Spring 2011. Pollen from 'Deja Vu' was deposited on emasculated flowers of 'Pink Mist' seedlings.

Received for publication 25 Oct. 2021. Accepted for publication 15 Dec. 2021.

Published online 1 February 2022.

J.G.C.-C. is the corresponding author. E-mail: jcruzc@chapingo.mx.

This is an open access article distributed under the CC BY-NC-ND license (https://creativecommons. org/licenses/by-nc-nd/4.0/).
In 2012, seeds from the crosses were sown. 'Utopia' was selected in 2018 and was propagated by rhizomes.

\section{Description and Performance}

The spathe has different colors on the external faces: a pinkish purple on one face (Fig. 1) and white on the other (Fig. 2). The inner face is white with a throat that is slightly pink (Fig. 1). The 'Utopia' calla is a viable horticultural option for producers in the mountainous areas of Veracruz at altitudes between 900 and $2500 \mathrm{~m}$. In the tropical highlands, it is recommended that one grows this calla under trees or artificial shade of $35 \%$ to $50 \%$. The general optimum temperature for the development of 'Utopia' ranges between 16 and $24^{\circ} \mathrm{C}$. Temperatures that stress 'Utopia' are less than $10^{\circ} \mathrm{C}$ and more than $28^{\circ} \mathrm{C}$. 'Utopia' was produced with rainwater; there are no studies on the effect of artificial irrigation. 'Utopia' grows in soils with adequate drainage, and the $\mathrm{pH}$ must be kept between 5.5 and 6.5 . In the field, the rhizomes are planted at $70 \times 70 \mathrm{~cm}$ or $60 \times$ $50 \mathrm{~cm}$ (Cruz-Castillo et al., 2008). Larger rhizomes go into production faster. A small rhizome produces floral scapes after 1 year of being planted (Cruz Castillo et al., 2008). Harvest is carried out when the floral scapes are fully showing their final color, just before the total opening of the spathe in the shape of

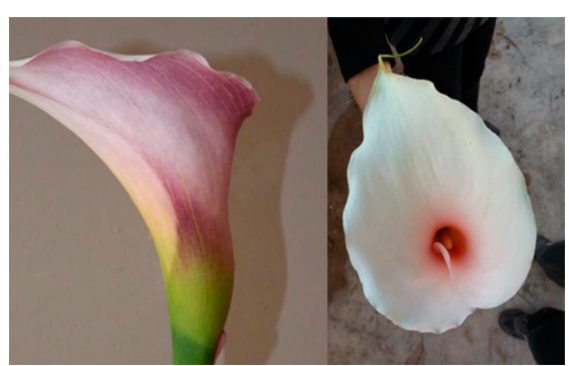

Fig. 1. Individual plant appearance. One external side of the 'Utopia' spathe is pinkish purple color (left). The inner face is white, with the throat slightly pink (right).

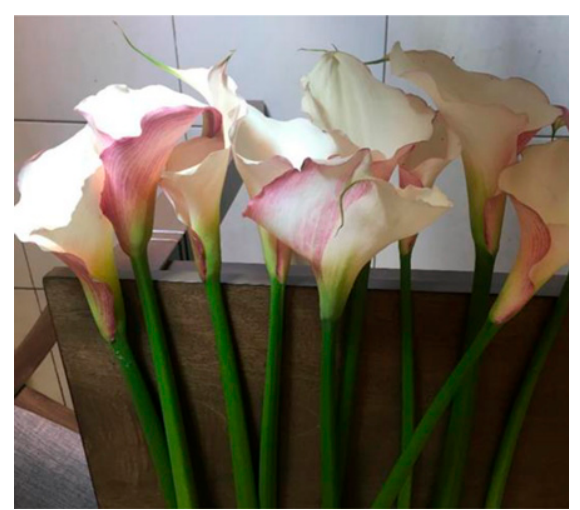

Fig. 2. Floral scapes of 'Utopia'. The external spathe has two different colors; one side is white and the other is pinkish purple.

a trumpet. This is 1 or $2 \mathrm{~d}$ before the pollen sheds. There are no studies on the vase life of 'Utopia', but it has managed to last up to $17 \mathrm{~d}$ in good condition after being harvested. A potted 'Utopia' plant can produce three to six floral scapes per year.

'Utopia' can be used as a garden plant, cut flower, and potted plant. The floral scape length of 'Utopia' is about $90 \mathrm{~cm}$, which is similar to the 'Creole' (white) calla perennial produced in Mexico and other countries in Latin America.

\section{Availability}

'Utopia' is registered in Mexico with the breeder's title no. 2720 with the National Seed Inspection and Certification System. Plants of this cultivar can be requested through the General Direction of Research and Postgraduate Studies in the Chapingo Autonomous University, Mexico (dgip.cai@chapingo.mx).

\section{Literature Cited}

Cruz-Castillo, J.G., and P.A. Torres-Lima. 2017. 'Deja Vu': A new calla lily (Zantedeschia aethiopica) cultivar. Rev. Chapingo Ser. Hort. 23(2): 97-101, https://doi.org/10.5154/r.rchsh.2017.01.005. Cruz-Castillo, J.G., P.A. Torres-Lima, M. AlfaroChimalgua, M.L. Albores-González, and J. Murguia-González. 2008. Vermicompost and postharvest stages of spathe development of 'Green Goddess' calla [Zantedeschia aethiopica (L) K. Spreng] in tropical conditions. Rev. Chapingo Ser. Hort. 14(2):207-212.

International Union for the Protection of New Varieties of Plants. 2011. Guidelines for the conduct of tests or distinctness, uniformity and stability: Cala (Zantedeschia Spreng.). International Union for the Protection of New Varieties of Plants, Geneva, Switzerland. 14 Jan. 2022. <https://www.upov.int/ edocs/mdocs/upov/en/tg/tg_177_2_proj.pdf $>$.

Kuehny, J.S. 2000. Calla history and culture. HortTechnology 10:267-274, https://doi.org/10.21273/ HORTTECH.10.2.267. 